\title{
Book review: Clovis Lithic Technology: Investigation of a Stratified Workshop at the Gault Site, Texas
}

\author{
John Edward Dockall \\ Prewitt and Associates, Inc.. 2105 Donley Drive, Suite 400, Austin, Texas, United States. \\ Email: JDockall@paiarch.com
}

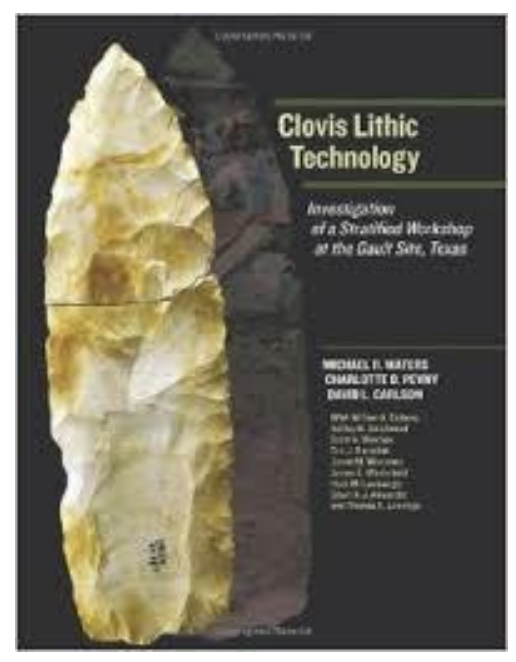

Clovis Lithic Technology: Investigation of a Stratified Workshop at the Gault Site, Texas by Michael R. Waters, Charlotte D. Pevny and David L. Carlson Texas A\&M University Press, 2011, pp. 226, pl. 99. ISBN 978-1-60344-278-7 http://www.tamupress.com/product/Clovis-Lithic-Technology,6711.aspx

Clovis Lithic Technology presents a detailed technological, typological, and spatial analysis and interpretation of the Clovis lithic assemblage from the Gault Site in central Texas. The Gault site itself is a sine qua non of Clovis sites and represents one of the few of such locales that can be identified as a workshop associated with this industry. The technical descriptions, published data, and interpretive detail of this volume make it a welcome addition to the growing body of new technological information on Clovis in general.

The book is organized into ten chapters based on the results of several Master's theses and Doctoral dissertations devoted aspects of the Gault Site lithic assemblage. Chapters 1 and 2 provide introductory background placing the Gault Site into temporal and regional perspective among other Clovis sites in North America. Included are discussions of site stratigraphy, chronology and site formation processes. Site formation processes at Gault have

Published by the School of History, Classics and Archaeology, University of Edinburgh ISSN: 2055-0472. URL: http://journals.ed.ac.uk/lithicstudies/

This work is licensed under a Creative Commons Attribution 2.5 UK: Scotland License. 
become increasingly important in light of more recent research on the pre-Clovis deposits at the site. Chapter 3 clarifies identification of the raw material and discussion of the organization of the blade and biface portions of the lithic technology at Gault. Chapter 4 is devoted to description and discussion of the blade technology. Included are detailed technological descriptions of blade cores, core tablets, crested blades, and cortical and noncortical blades. Blade attributes are also compared to known Clovis blade cache assemblages such as Pavo Real and Anadarko but also to blades found elsewhere at Gault beyond the workshop deposits in Excavation Area 8. While blades from the workshop deposits bear little resemblance to the cache blades, those from Gault outside the workshop deposits bear striking technology and quality similarities to cache blades from Pavo Real and Anadarko. Chapter 5 details the technology and typology of bifaces found at the Gault Site. Most welcome in this chapter is a good technical discussion of biface production debitage and the importance of overshot techniques in shaping and thinning Clovis bifaces. As with blades, finished and complete bifaces from Gault are evaluated by comparison to known Clovis biface caches like Hogeye and de Graffenried locales. This chapter is also enlightening in its contributions to understanding Clovis point manufacturing trajectories. Chapter 6 is a welcome explanation of the typological and technological character of Clovis endscrapers and other edge-modified tools from Gault. It demonstrates the range of other activities that were also conducted at the site in support of the workshop tasks. Types of edge modified flakes include convex-end unifaces with lateral spurs on either side of the bit and some with hafting notches. Discussion of this part of the Clovis assemblage provides some useful insight into aspects of the technology seldom seen from other sites that have greater numbers of points and fewer other types of tools. Chapter 7 is a complementary to Chapters 4-7 and is devoted to detailed microscopic use wear analysis results of a suite of selected implements that include projectile points, bifaces, a knife, chopper, endscrapers, blades and blade fragments, and modified and unmodified flakes. Results indicate that most tool use was of limited duration. Use wear attributes such as polish and striations are not well represented. Chapter 8 is devoted to the analysis and interpretation of recovered faunal remains from Clovis deposits at Gault. The suite of identified species include horse, bison, deer, rabbits, canids, and a number of other smaller mammals and small, medium and large birds, and turtle. Preservation was noted to be extremely poor (with high fragmentation) and thus results were limited. Spatial organization of workshop activities is presented in Chapter 9. Employing typological and technological results from previous chapters, this chapter applies artifact spatial patterning around features in Units $3 \mathrm{a}$ and $3 \mathrm{~b}$ to discuss feature-related tasks and discard behavior. Results suggest significant differences between these two units, perhaps related to different tasks and different patterns of artifact and faunal discard. It also hints at the presence of some type of activity area on the northern end of the excavation block. Chapter 10 is the summary and synthesis of the preceding chapters. Patterns of tool use, tool manufacture and discard at Excavation Area 8 and how the deposits are interpreted as workshop debris associated with a larger residential base camp are clear. Gault is unique in several aspects. There is no extinct Pleistocene megafauna, the lithic assemblage is almost entirely Edwards chert rather than a mix of exotic raw materials, and the entire manufacture, use, and discard sequence is present.

Clovis Lithic Technology is a welcome addition to the literature on Paleo-Indian technology. The volume is clearly written and well-organized. Metric, technological and typological data are presented for the entire assemblage. The technical interpretations for blade and biface manufacture are sound and based on a thorough study of the Gault lithic assemblage. Typological and functional discussions of the edge modified tools add to the overall value of the monograph as a research tool. While there is not a lot of direct comparison to assemblages from other Clovis sites in North America, the information is presented to assist the reader in that regard. 